\title{
Waterlogging risk assessment for winter wheat using multi-source data in the middle and lower reaches of Yangtze River
}

\author{
Yuanyuan Chen ${ }^{1,2}$, Jingfeng Huang ${ }^{1,2}$, Xiaodong Song ${ }^{1,2^{*}}$, Hongyan $\mathrm{Wu}^{3}$, Shaoxue Sheng ${ }^{4}$, \\ Zhixiong Liu ${ }^{5}$, Xiuzhen Wang ${ }^{6}$ \\ (1. Key Laboratory of Agricultural Remote Sensing and Information System, Zhejiang University, Hangzhou 310058, China; \\ 2. Institute of Remote Sensing and Information Technology Application, Zhejiang University, Hangzhou 310058, China; \\ 3. Jiangsu Meteorological Bureau, Nanjing 210008, China; \\ 4. Anhui Meteorological Information Center, Anhui Meteorological Bureau, Hefei 230031, China; \\ 5. Wuhan Regional Climate Center, China Meteorological Administration, Wuhan 430074, China; \\ 6. Institute of Remote Sensing and Earth Sciences, Hangzhou Normal University, Hangzhou 311121, China)
}

\begin{abstract}
Waterlogging is a serious agro-meteorological disaster caused by excessive soil water, which usually causes tremendous crop yield losses. The region of middle and lower reaches of Yangtze River in China is an important production base of winter wheat, and is an area prone to waterlogging. The risk assessment of winter wheat waterlogging can provide more thorough understanding about the risk-prone environment related with food safety in this region. This study combined a variety of environmental and agricultural factors and assessed the waterlogging risk of winter wheat from the aspects of sensitivity of hazard formative environments, hazard risk, and vulnerability of hazard-affected body using multi-source data. Furthermore, it constructed a compound waterlogging risk assessment model to classify the study area into high, relatively high, moderate, and low risky areas, respectively. The results showed that the proposed model could more comprehensively reflect the occurrence mechanism of winter wheat waterlogging by synchronizing geographical, agricultural, and meteorological factors. The waterlogging regionalization based on the model could reasonably represent the spatial distribution and differentiate regional characteristics of winter wheat waterlogging in the study area.
\end{abstract}

Keywords: waterlogging, hazard formative environments, vulnerability, risk assessment

DOI: $10.25165 /$ j.ijabe.20181105.3246

Citation: Chen Y Y, Huang J F, Song X D, Wu H Y, Sheng S X, Liu Z X, et al. Waterlogging risk assessment for winter wheat using multi-source data in the middle and lower reaches of Yangtze River. Int J Agric \& Biol Eng, 2018; 11(5): 198-205.

\section{Introduction}

Waterlogging is a kind of agro-meteorological disaster caused by excessive soil water, which might be crop-specific but the crop symptoms of waterlogging are generally uniform, e.g., anaerobic metabolism in roots due to hypoxia stress ${ }^{[1-3]}$, decreased stomatal conductance and leaf water potentials ${ }^{[4]}$, enhanced root and leaf senescence $^{[5,6]}$, deficiencies of energy, carbohydrate and nutrients ${ }^{[7]}$, and eventually, restricted crop growth and grain yield ${ }^{[8-10]}$. It is estimated that about $10 \%-15 \%$ of the world's wheat acreage are affected by waterlogging ${ }^{[11,12]}$.

The region of middle and lower reaches of the Yangtze River is one of the most important winter wheat growing area which

\section{Received date: 2017-02-05 Accepted date: 2018-06-07}

Biographies: Yuanyuan Chen, PhD candidate, research interests: agricultural disaster monitoring, Email: xiaoxiaoyuan@zju.edu.cn; Jingfeng Huang, PhD, Professor, research interests: agricultural remote sensing and information technology application, Email: hjf@zju.edu.cn; Hongyan Wu, Senior Engineer, research interests: applied meteorology, Email: jsqx_zqzb@126.com; Shaoxue Sheng, Senior Engineer, research interests: applied meteorology, Email: shengshxue@sohu.com; Zhixiong Liu, Senior Engineer, research interests: applied meteorology, Email: liuzhix2008@yahoo.com.cn; Xiuzhen Wang, $\mathrm{PhD}$, Professor, research interests: agricultural remote sensing and information technology application, Email: wxz0516@sina.com.

*Corresponding author: Xiaodong Song, $\mathrm{PhD}$, research interests: land surface process model. College of Natural Resources and Environmental Science, Zhejiang University, 866 Yuhangtang Road, Hangzhou 310058, Zhejiang, China. Email: xdsongy@zju.edu.cn. accounts for about $15 \%$ of the total wheat acreage in China. The dominant monsoon climate in this region, especially in the spring from March to May, usually carries abundant precipitation and, as a consequence, varying degrees of waterlogging were jointly determined by local climate, terrain, soil properties, and underground water table level. The regions with clay, low-lying terrain or poor drainage are usually more vulnerable to waterlogging ${ }^{[13-15]}$. Historical statistical data of waterlogging in the three provinces, i.e., Hubei, Jiangsu, and Anhui, along the lower reaches of the Yangtze River clearly demonstrated the coverage and severity of waterlogging to local agriculture. The statistical data showed that there were about $806200 \mathrm{hm}^{2}$ farmlands affected by waterlogging, and in which about $470700 \mathrm{hm}^{2}$ were inundated areas, annually in Hubei Province ${ }^{[16]}$. For Jiangsu Province, 7 out of 10 meteorological disasters in recent years could be attributed to waterlogging. From 1981 to 2005, the waterlogging occurred with a frequency of about 2.5 years in Jianghuai plain area of Anhui Province and caused about $10 \%$ loss of winter wheat production. In severe waterlogging years, e.g., $1985,1991,1998,2003$, and 2005, more than $20 \%$ winter wheat yield losses were observed ${ }^{[17,18]}$. Therefore, it is of critical importance to gain more thorough understanding about the prone environment and risk of waterlogging in this region.

There were extensive literatures about risk assessment and zoning of agricultural meteorological disasters, e.g., flood, drought, and chilling/freezing, focusing on the probabilistic risk assessment model $^{[19-21]}$, hazard risk or vulnerability of hazard-affected 
body $^{[22-26]}$, and corresponding risk indices ${ }^{[27-29]}$. Current works about crop waterlogging mainly focused on the symptom identification and corresponding indices, influences on crop yields ${ }^{[30-32]}$, biochemical mechanism, variety screening, and genetic improvement ${ }^{[11,33-35]}$. To our knowledge, waterlogging loss assessment and risk regionalization still did not attain enough attention, compared with its huge influence on winter crop production in China.

Most of the works about waterlogging disaster assessment are based on one or two specific meteorological or remote sensing variables, such as waterlogging frequency and crop production $\operatorname{loss}^{[36]}$, AVHRR and MODIS derived waterlogging frequency and hazard variables ${ }^{[37]}$, and spectral indices, e.g., the normalized difference water index (NDWI) and the modified normalized difference water index ${ }^{[38]}$. It's not surprised to find that most of the above-mentioned works only take yield losses, hazard risk, and vulnerability into consideration from the meteorological point of view. However, the waterlogging hazard formative environments (e.g., topography and geomorphology, soil, and hydrology factors), which are indispensable during disaster formation, are usually omitted.
In this paper, the middle and lower reaches of Yangtze River were taken as the study area. This study integrated the sensitivities of waterlogging hazard formative environments, hazard risk, and vulnerability of hazard-affected body and built a synthetic waterlogging risk assessment model. A series of environmental factors, including geographical, agricultural, and meteorological variables such as slope, low-lying degree, soil waterlogging index, climate risk probability, physical exposure of winter wheat, and disaster-resisting performance index, were combined to facilitate the building of a comprehensive winter wheat waterlogging risk assessment model.

\section{Data and methods}

\subsection{Study area}

The middle and lower reaches of Yangtze River, including Anhui, Jiangsu, and Hubei Provinces, situate between $29^{\circ} 05^{\prime}$ $35^{\circ} 20^{\prime} \mathrm{N}$ and $108^{\circ} 21^{\prime}-121^{\circ} 57^{\prime} \mathrm{E}$ (Figure 1). The diverse climates of this region include warm temperate zone, semi-humid, and subtropical humid monsoons. The annual precipitation is about $700-1600 \mathrm{~mm}$ and mainly concentrates in the spring and summer. The annual mean temperature ranges from $13^{\circ} \mathrm{C}$ to $18^{\circ} \mathrm{C}$.

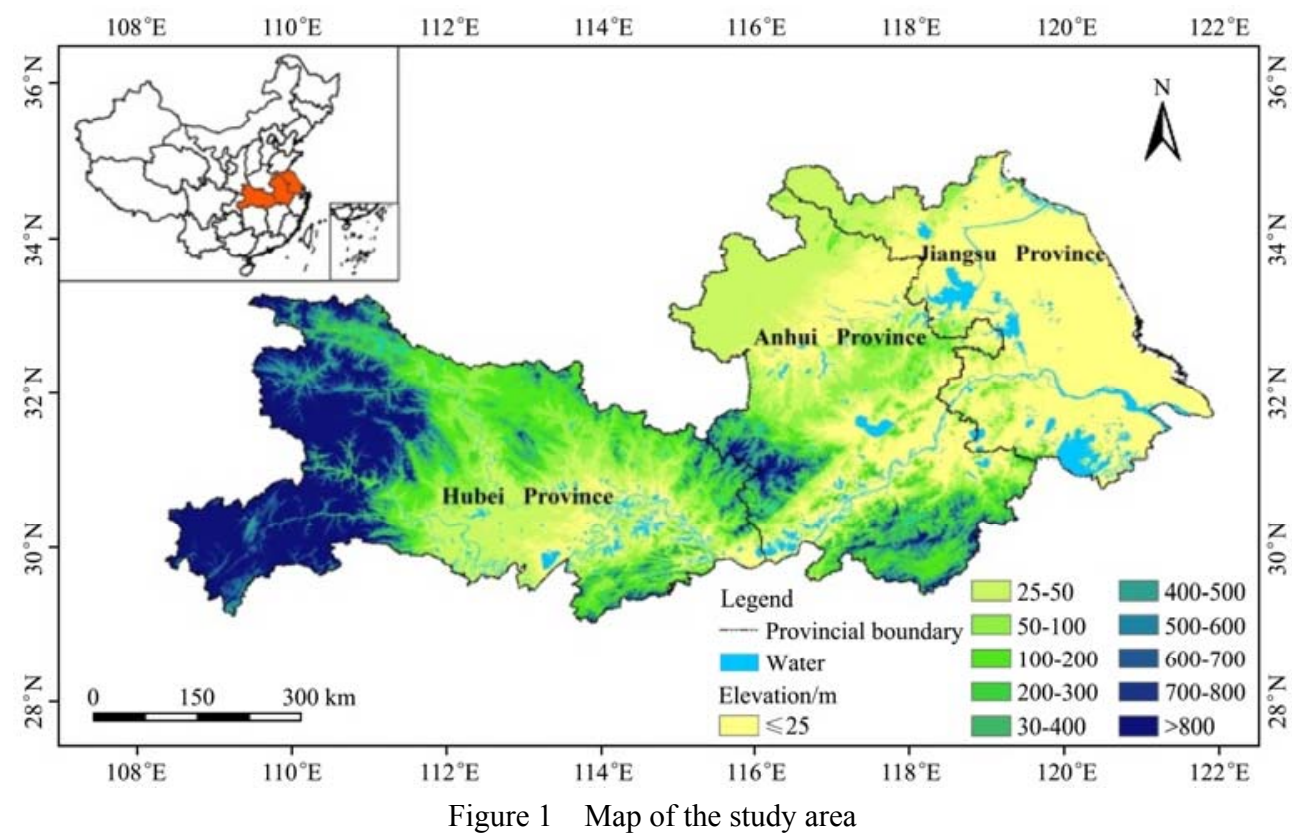

\subsection{Data}

The soil texture data was provided by the International Soil Reference and Information Center (ISRIC). The spatial resolution of this data is $1 \mathrm{~km}$, and the soil texture fractions of sand (SNDPPT) and clay (CLYPPT) in percent are of interest in this study. The $90 \mathrm{~m}$ resolution SRTM digital elevation data (DEM) was obtained from Geospatial Data Cloud website (http://www.gscloud.cn/). The geographic data was obtained from the National Basic Geographic Information System database (http://nfgis.nsdi.gov.cn/ asp/userinfo.asp). The $500 \mathrm{~m}$ resolution MODIS Land Cover Type product (MCD12Q1) provided by NASA's Earth Observing System and Data and Information System (EOSDIS) was used to derive the land cover information. The meteorological and historical statistic data of winter wheat, including daily precipitation, daily sunlight hours, and winter wheat acreage and production data from 1971 to 2010 were acquired from local meteorological bureaus in the study area.

\subsection{Waterlogging risk assessment model}

As the waterlogging disaster is the compound effects of waterlogging formative environment (e.g., topography and geomorphology, soil, and hydrology factors), disaster-causing factors (e.g., precipitation), and hazard-affected body (e.g., winter wheat), we focused on the three factors in waterlogging risk assessment ${ }^{[39]}$ and proposed a waterlogging risk assessment model of winter wheat as following:

$$
D_{r}=D_{s} \times D_{h} \times D_{v}
$$

where, $D_{r}$ is the waterlogging risk assessment value; $D_{s}$ is the sensitivity of waterlogging hazard formative environments determined by slope, low-lying degree, and soil physical properties (Equation (3)); $D_{h}$ is the hazard risk of meteorological factors (Equation (9)); and $D_{v}$ is the vulnerability of hazard-affected body determined by the winter wheat acreage and regional disaster-resister ability (Equation (12)). The larger the value of $D_{r}$, the greater the risk of waterlogging disaster will be. The technical flow chart was designed as shown in Figure 2 to get the value of $D_{r}$, and the following sub-sections are the details.

To eliminate the effects of different dimensionalities among 
various factors, all the indicators were normalized into $[0,1]$ except the low-lying degree index which could not be refined numerically.
The Analytical Hierarchy Process (AHP) method was adopted to determine the corresponding index weight ${ }^{[40]}$.

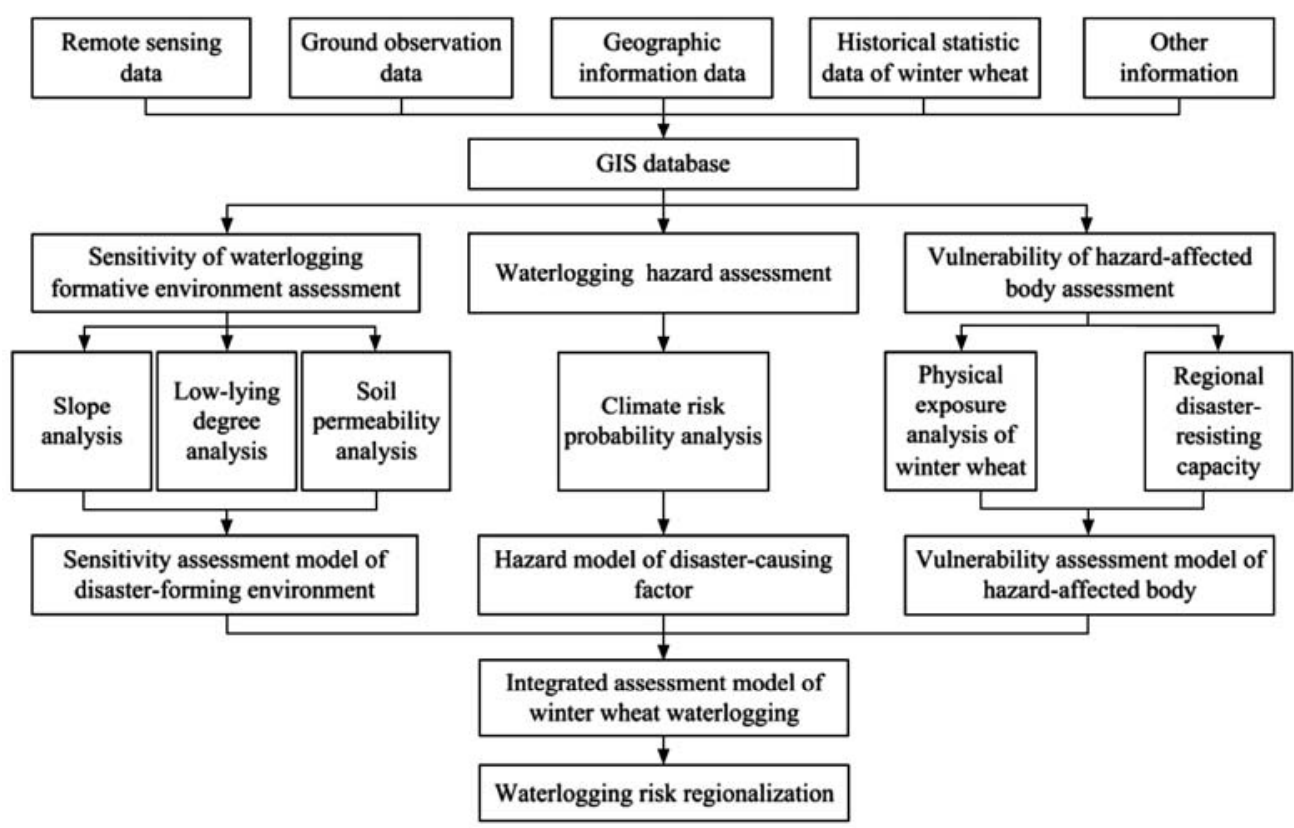

Figure 2 Technical flow of risk assessment and zoning of winter wheat waterlogging disaster

2.3.1 Sensitivity assessment of waterlogging formative environment

The formative environment of waterlogging is mainly composed by climate (esp. precipitation), topography and geomorphology, soil and vegetation, and hydrology factors. The precipitation is one of the most determining factors in the formation of waterlogging, so it's reasonable to take precipitation as the major disaster-causing factor, while slope, soil, and low-lying degree as the sensitive ones.

(1) Slope

The slope is the steep or gentle degree of surface units and has great influences on surface runoff. Under the same rainfall condition, the greater slope could cause less infiltration, and vice versa. The SRTM $90 \mathrm{~m}$ resolution DEM data was used to derive the slope data.

(2) Low-lying degree

The low-lying parts of lands are prone to waterlogging. The study area was divided into different watersheds and sub-watersheds to classify the low-lying degree. The historical highest water levels of each watershed were acquired from local water conservancy yearbook, and the flood depths were calculated correspondingly. The low-lying degree $\left(L_{l}\right)$ of a specific watershed or sub-watershed was classified into three levels, i.e., 1 , 2 , and 3 , in which 1 means high low-lying degree, 2 for moderate degree, and 3 represents no low-lying, based on elevation using the Jenks natural breaks classification method. It's noted that the first threshold of low-lying degrees for a specific watershed should be larger than its historical highest water level, and the elevation difference of each category should be greater than 1.5 times of the flood depth. For sub-watershed without the highest water level records, the thresholds of its upstream sub-watershed were used.

(3) Soil waterlogging index

The infiltration capacities of different soil textures are not the same. Generally, the permeability of soil increases with the proportion of sandy compositions, but decreases with clay proportion ${ }^{[41]}$.

In this study, it proposed a soil waterlogging index $S_{w}$. It represents the influence of soil texture on waterlogging and is calculated by using the soil texture fractions of sand (SNDPPT) and clay (CLYPPT) in percent as follows:

$$
-S_{w}=\frac{P_{\text {clay }}-P_{\text {sand }}}{P_{\text {clay }}+P_{\text {sand }}}
$$

where, $P_{\text {clay }}$ and $P_{\text {sand }}$ are clay and sand percentages, respectively. The smaller the value $S_{w}$, the higher grittiness and permeability of that soil will be.

Hence, the comprehensive evaluation model of the sensitivity of waterlogging hazard formative environments $\left(D_{s}\right)$ is defined as:

$$
D_{s}=\frac{w_{1} \times S_{w}+w_{2} \times(1-\text { Slope })}{L_{l}}
$$

where, $w_{1}$ and $w_{2}$ are the weights of $S_{w}$ and slope respectively, and their values are determined by using the AHP method. Because the slope and low-lying degree $\left(L_{l}\right)$ are negative indicators compared with $S_{w}$ for the sensitivity of waterlogging hazard formative environments, the form of 1-Slope was used and divided by $L_{l}$ to construct the sensitivity evaluation model.

2.3.2 Waterlogging hazard risk assessment model

(1) Winter wheat waterlogging index

A national standard issued by the China meteorological administration (QX/T 107-2009) was adopted from the meteorological point of view to grade the waterlogging severity of winter wheat. The winter wheat waterlogging index is defined as:

$$
Q_{w}=b_{1} \frac{R}{R_{\max }}+b \frac{D_{R}}{D}-b_{3} \frac{S}{S_{\max }}
$$

where, $Q_{w}$ is the waterlogging index; $R$ is the sum of precipitation in 10 consecutive days, and $R_{\max }$ is the maximum $R$ during the study period (i.e., 1971-2010); $D_{R}$ is the sum of rainy days in 10 consecutive days, and $D$ is a constant of $10 ; S$ is the sum of actual sunlight hours in 10 consecutive days, and $S_{\max }$ is the maximum possible sunshine duration of 10 consecutive days from the astronomical point of view; and $b_{1}, b_{2}$, and $b_{3}$ are coefficients of precipitation, rainy days, and sunlight days, where the reference values for $b_{1}, b_{2}$, and $b_{3}$ are in the ranges of $0.75-1.00,0.75-1.00$, 
and $0.50-0.75$, respectively.

According to the historical waterlogging occurrence data, the winter wheat waterlogging index $\left(Q_{w}\right)$ was divided into four grades as shown in Table 1 (QX/T 107-2009).

Table 1 Waterlogging index range and the corresponding waterlogging grades for winter wheat

\begin{tabular}{cc}
\hline Waterlogging index $Q_{w}$ & Waterlogging grade \\
\hline$<0.8$ & No \\
$0.8-1.0$ & Mild \\
$1.0-1.2$ & Moderate \\
$\geq 1.2$ & Severe \\
\hline
\end{tabular}

(2) Waterlogging hazard

The meteorological data generally follow the normal distribution $^{[42]}$. The $Q_{w}$ indices of 203 meteorological stations over the study area from 1971 to 2010 were checked, and it is found that most of them followed the normal distribution. A transformation between the ordinary coordinates and probability coordinates was performed for the sites that did not satisfy the normal distribution ${ }^{[43]}$. The probability of waterlogging can be expressed as:

$$
f(x)=\frac{1}{\sigma \sqrt{2 \pi}} e^{\frac{-(x-\mu)^{2}}{2 \sigma^{2}}}
$$

where, $x$ is the value of $Q_{w} ; \mu$ the average value of $Q_{w}$ for a specific location, and $\sigma$ the standard deviation of $Q_{w}$.

For a certain location, the probability density function $f(x)$ was integrated to obtain waterlogging risk probabilities for the mild $\left(D_{h 1}\right)$, moderate $\left(D_{h 2}\right)$, and severe $\left(D_{h 3}\right)$ ones as following:

$$
\begin{aligned}
& D_{h 1}=\int_{Q_{w 1}}^{Q_{w 2}} f(x) d x \\
& D_{h 2}=\int_{Q_{w 2}}^{Q_{w 3}} f(x) d x \\
& D_{h 3}=1-\int_{-\infty}^{Q_{w 3}} f(x) d x \\
& D_{h}=1-\int_{-\infty}^{Q_{w 1}} f(x) d x
\end{aligned}
$$

where, $Q_{w 1}, Q_{w 2}$, and $Q_{w 3}$ are mild, moderate, and severe waterlogging thresholds for winter wheat, respectively. The summation of mild-to-severe waterlogging probabilities was used as the waterlogging hazard index $\left(D_{h}\right)$.

\subsubsection{Vulnerability assessment of hazard-affected body}

The vulnerability of hazard-affected body can be evaluated from the aspects of physical exposure, damage sensitivity, and disaster-resisting ability ${ }^{[44,45]}$. The sensitivity of hazard bearing body mainly depends on its physical structure and development stage, and there is no unified index that can be used to assess the humidity resistance ability of crop. So the physical exposure and disaster-resisting ability were selected to build the vulnerability assessment model for hazard-affected body.

The physical exposure of hazard-affected body is represented by the ratio of winter wheat planting area and the total agricultural acreage in each county:

$$
V_{e}=\frac{A_{w}}{A_{a}}
$$

where, $A_{w}$ and $A_{a}$ are winter wheat acreage from historical statistics and the total acreage of each county acquired from MODIS (MCD12Q1), respectively.

The regional disaster-resisting ability $\left(V_{d}\right)$ represents the human interventions taken to protect the hazard-affected body from certain agricultural disaster ${ }^{[46]}$. The $V_{d}$ is represented by the regional agricultural level index, i.e., the fraction of crop yield of this region to the entire study area:

$$
V_{d}=\frac{1}{n} \sum_{i=1}^{n} \frac{Y_{i}}{S_{i}}
$$

where, $Y_{i}$ is crop yield of the $i$-th year, and $S_{i}$ is the total yield of the study area in the $i$-th year (total 231 administrative units are used).

The vulnerability assessment model for hazard-affected body $\left(D_{v}\right)$ is defined as:

$$
D_{v}=w_{a} \times V_{e}+w_{4} \times\left(1-V_{d}\right)
$$

where, $w_{3}$ and $w_{4}$ are the physical exposure of winter wheat $\left(V_{e}\right)$ and the disaster-resisting ability $\left(V_{d}\right)$, respectively. The values of $w_{3}$ and $w_{4}$ are calculated by the AHP method.

\subsubsection{Spatial analysis}

The data used in this study have different spatial resolutions, i.e., $90 \mathrm{~m}, 500 \mathrm{~m}$, and $1 \mathrm{~km}$. All the raster data were transformed into $1 \mathrm{~km}$ by the bilinear interpolation method to facilitate the following spatial analysis. The county level statistic data were transformed into $1 \mathrm{~km}$ raster data by the inverse distance weighted interpolation (IDW) method. The sensitivity, hazard, and vulnerability maps of waterlogging were generated using the above mentioned models. The grade of waterlogging was reclassified by using the Natural Breakpoint Classification method (Jenks) ${ }^{[47]}$.

\section{Results and discussion}

\subsection{Waterlogging sensitivity}

The spatial distributions of slope, low-lying degree, and soil waterlogging index used in waterlogging sensitivity analysis are shown in Figures 3a-3c), respectively. The three factors were integrated by using Equation (4) to generate the vulnerability map of waterlogging hazard formative environment as shown in Figure $3 \mathrm{~d}$.

Figure $3 \mathrm{~d}$ clearly shows that the highly sensitive regions to waterlogging mainly concentrated in the plain areas, and the regions scattered along the major rivers, polder, and estuary areas. On the contrary, the less sensitive regions mainly distributed in the mountainous and hilly areas.

\subsection{Waterlogging hazard}

The spatial distribution of waterlogging risk probabilities of mild, moderate, and severe categories are shown in Figures 4a-4c), respectively. It shows that the waterlogging risk probabilities had obvious latitudinal distribution characteristics and were generally consistent with the distribution of precipitation in spring. The risk probability values of mild, moderate, and severe categories were $10.12 \%, 6.32 \%$, and $5.54 \%$ on average for the entire study area, respectively. The waterlogging hazard distribution map (Figure 4d) shows a similar pattern, i.e., a latitudinal distribution pattern from north to south in an increasing order.

\subsection{Waterlogging vulnerability}

Figures 5a-5b shows the physical exposure and disaster-resisting capacity index of winter wheat. The raw data are county-based and are resampled into $1 \mathrm{~km}$ spatial resolution using the IDW interpolation method.

Figure 6 shows the spatial distribution of vulnerability of hazard-affected winter wheat. The high vulnerability areas mainly concentrated in the north part of Anhui Province. Most of the moderate and low vulnerability areas distributed in the plain and hilly regions of Jiangsu and Anhui Provinces, and large part of Hubei Province was dominated by the relatively high vulnerability areas. 


\subsection{Integrated waterlogging risk zoning}

The waterlogging sensitivity (Figure 3d), hazard risk probability (Figure 4d), and vulnerability (Figure 6) were integrated by using Equation (1), and the result is shown in Figure 7. It shows that the high to relatively high waterlogging risk areas mainly concentrated in the plain regions in Hubei
Province, and the plain and polder areas along Yangtze River across Anhui and Jiangsu Provinces. These regions have abundant precipitation in spring (annual average ranges from 300 $\mathrm{mm}$ to $628 \mathrm{~mm}$ ), the dominated topographies are lowlands with numerous rivers and lakes, and the major soil textures are viscous paddy and red soil.

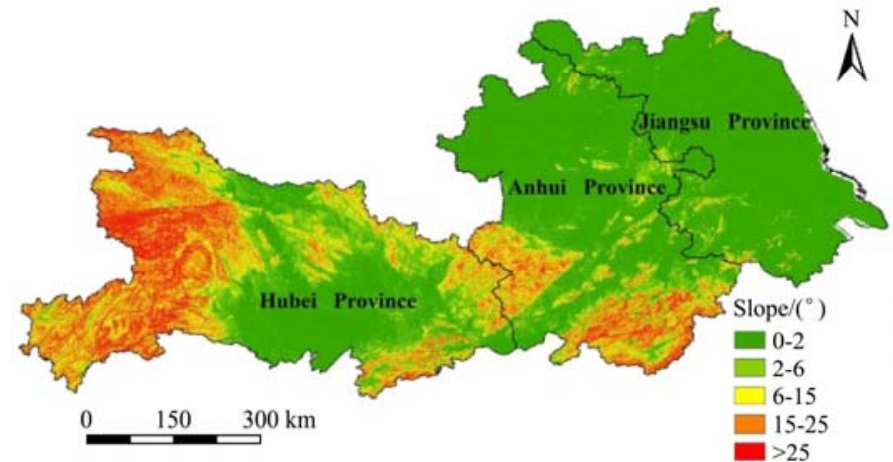

a. Slope

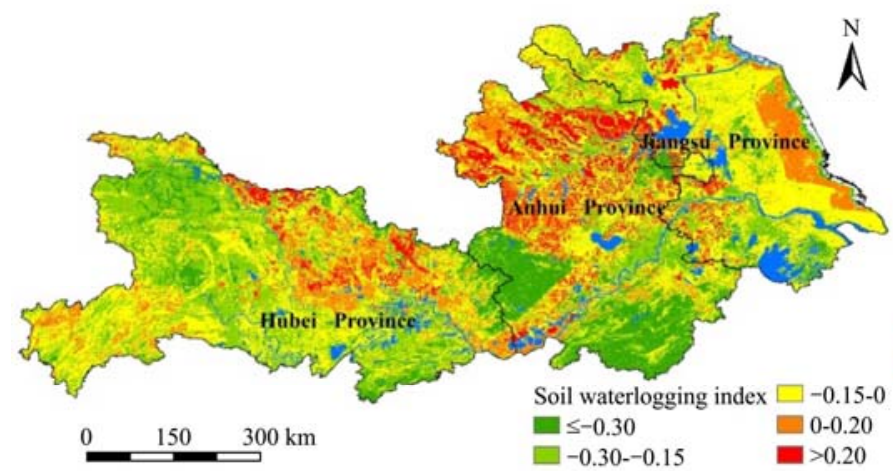

c. Soil waterlogging index

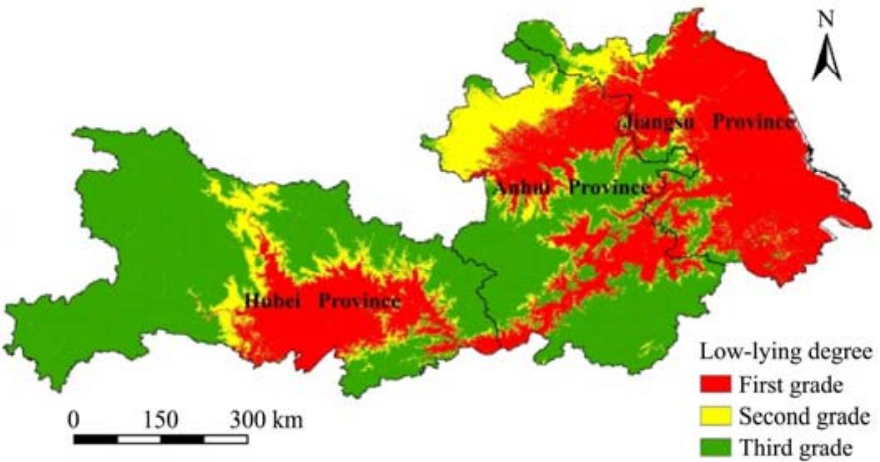

b. Low-lying degree

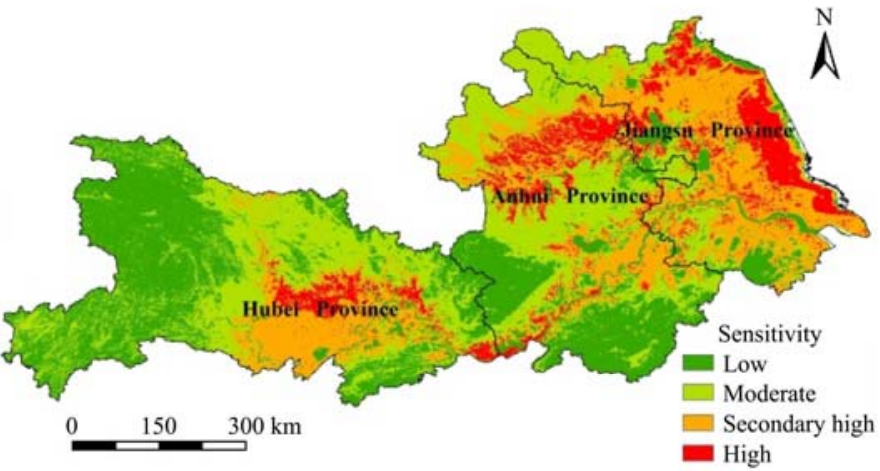

d. Waterlogging sensitivity map

Figure 3 Spatial distributions of the factors used in waterlogging sensitivity analysis

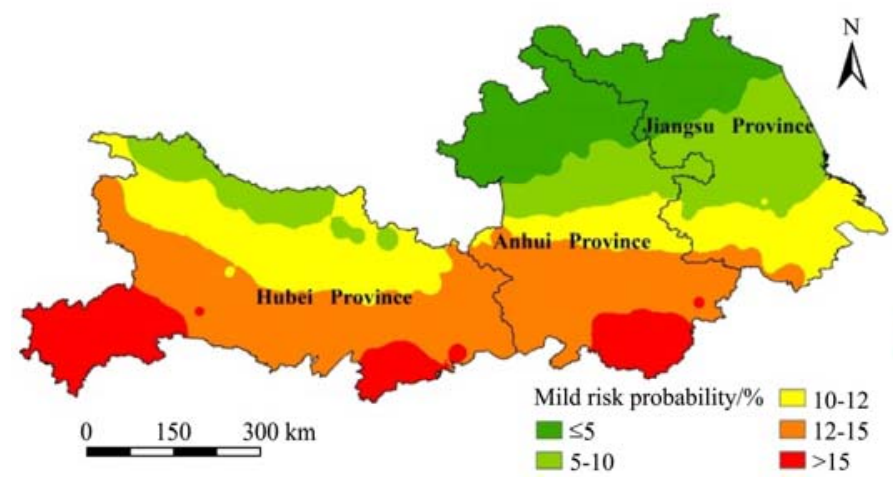

a. Mild

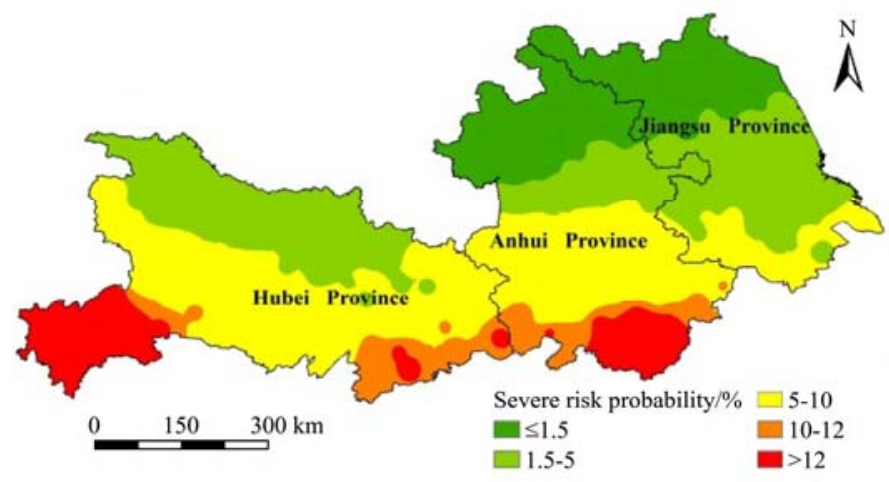

c. Severe

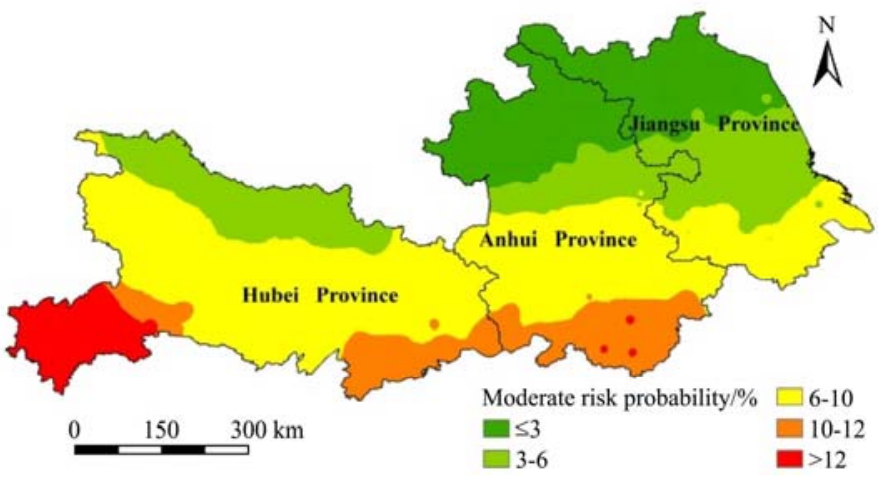

b. Moderate

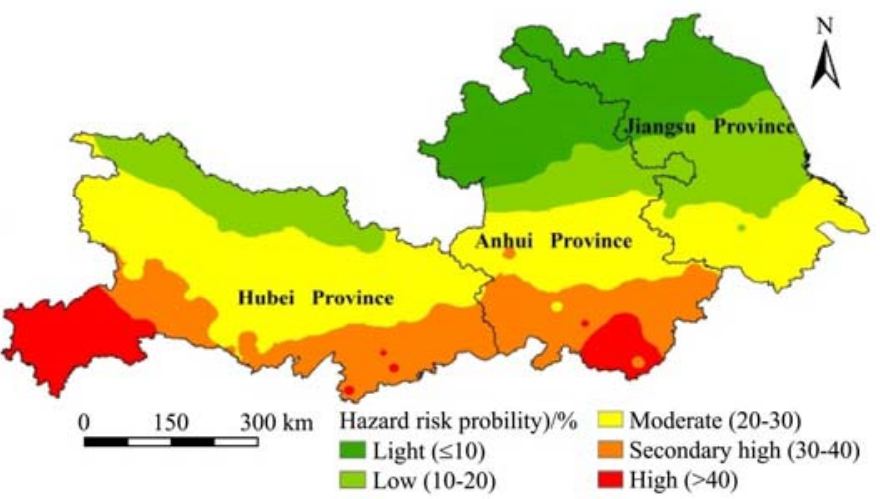

d. The waterlogging hazard map

Figure 4 Spatial distributions of waterlogging risk probabilities 


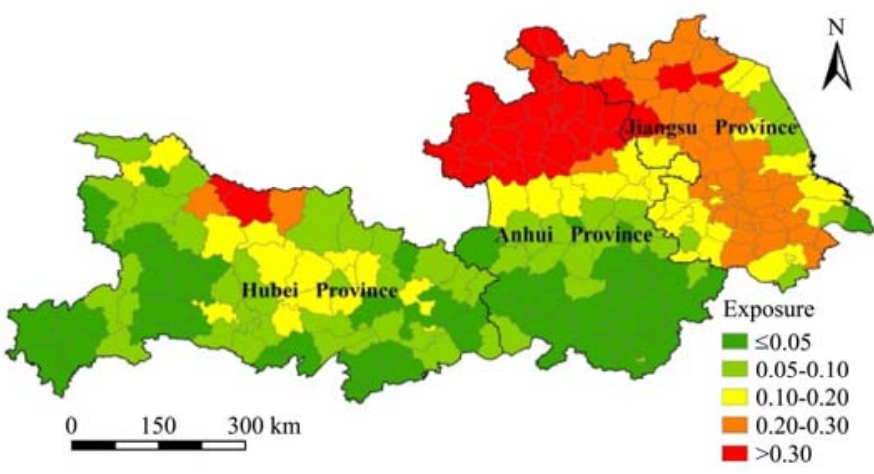

a. Physical exposure of winter wheat

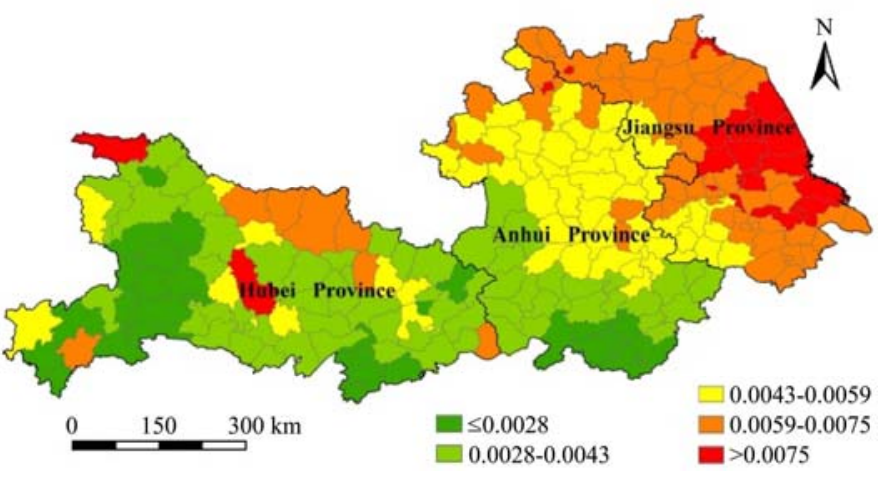

b. Disaster-resisting capacity index

Figure 5 Spatial distributions of physical exposure of winter wheat and disaster-resisting capacity index

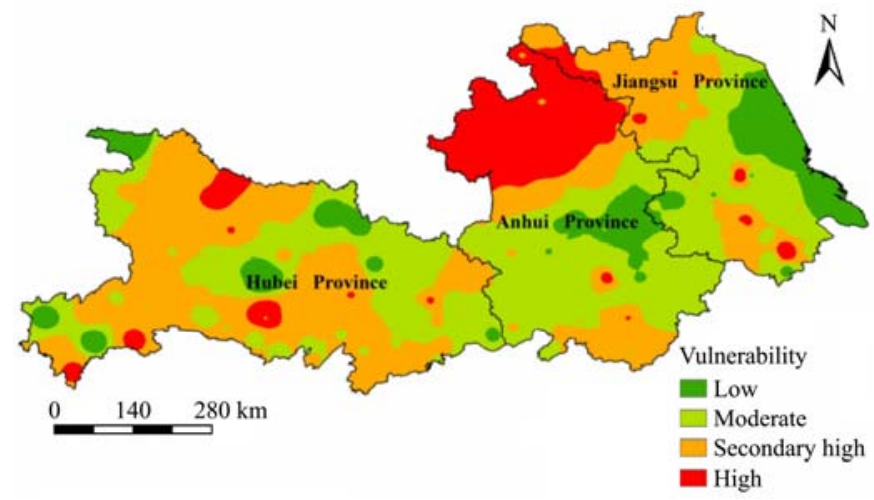

Figure 6 Spatial distribution of the vulnerability of hazard-affected body

The moderate waterlogging risk areas mainly distributed in the central area of Jiangsu and Anhui Provinces, and the hilly areas and southwest mountainous areas in Hubei Province. The central area of Jiangsu and Anhui Provinces has less intensive precipitation during spring. The high-risky and moderate-risky areas are mixed together in parts of the hilly areas and southwest mountainous areas of Hubei Province. These regions have been observed to have abundant rainfall, especially in the southwest mountain areas.

The low waterlogging risky regions mainly concentrated in the north plains of Anhui and Jiangsu Provinces and some mountainous areas in Hubei and Anhui Provinces. The north of Anhui and Jiangsu Provinces had minimal risk of waterlogging due to less precipitation.

\subsection{Discussion}

Precipitation is one of the most important environmental factors determining waterlogging severity. It is found that the spatial distribution of waterlogging hazard generally exhibited latitudinal characteristics in decreasing order of severity from south to north in the study area, similar with the spatial pattern of precipitation. However, the waterlogging occurrence at local scale is perplexed by multiple environmental factors, and different regions showed differing waterlogging sensitivities. For example, the waterlogging risk of northern parts of Anhui and Jiangsu Provinces mainly depends on precipitation; while for the southern part of the two provinces with abundant precipitation, the waterlogging severity showed close relationship with terrain, soil texture, and disaster-resisting capacity.

The high and relatively high risk areas mainly distributed in the plain regions of Hubei Province, and the plain and polder areas along Yangtze River across Anhui and Jiangsu Provinces. The low waterlogging risky regions mainly concentrated in the northern plains of Anhui and Jiangsu Provinces featured by less

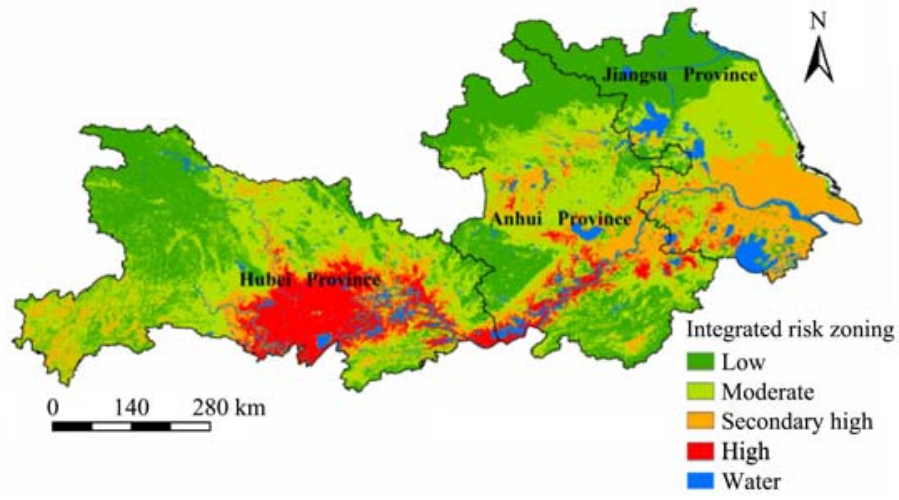

Figure 7 Integrated waterlogging risk map (zoning) of winter wheat

precipitation, and some mountainous areas in Hubei and Anhui Provinces with relatively smaller physical exposure of winter wheat, lower disaster-resisting capacity, and higher elevation.

The high waterlogging sensitive areas generally scattered in areas with flat terrain and higher clay proportion. The vulnerability analysis showed that the highest physical exposure of winter wheat made northern part of Anhui Province more vulnerable to waterlogging. Considering the relative flat terrain of the high and moderate risk regions, the waterlogging risk could be greatly alleviated by improving local irrigation and drainage facilities.

This study emphasized the compound effects of multiple environmental factors in evaluating waterlogging risk at regional scale. Under this framework, the waterlogging hazard formative environment, waterlogging hazard, and hazard-affected body could be integrated to evaluate the waterlogging risk at a relative fine spatial resolution by including a wide range of geographical, agricultural, and meteorological factors. The proposed waterlogging risk assessment model takes the potential waterlogging influences from topography, soil, and meteorology aspects into consideration, and it's more comprehensive compared with previous waterlogging risk researches which mainly focused on the meteorological waterlogging ${ }^{[18,36,48]}$. For example, the western mountainous and central regions of Anhui Province were labelled as higher waterlogging risk areas, and the eastern region of Hubei Province and the south western region of Jiangsu Province were all labelled as high risk waterlogging area in previous researches ${ }^{[16,36,48]}$. According to model in this study, however, the western mountainous areas in Anhui Province were low-risk area due to small winter wheat acreage, higher grittiness and permeability of soil, and higher elevation; while the central areas of Anhui Province was classified as moderate-risk area due to the 
relative higher elevation and smoother drainage capacities than the low-lying areas along the Huai River of Anhui Province. The eastern regions of Hubei Province were classified as high, relatively high and moderate risk areas by taking varied terrain and soil permeability into consideration. For Jiangsu Province, it is found that the south western region actually had some moderate-risk areas, especially in the lower mountainous and hilly areas, by including the terrain factor. It is considered that the aggregative model based on multi-source data could significantly improve the reliability and accuracy of waterlogging risk assessment.

\section{Conclusions}

This study quantitatively assessed the sensitivity, hazard risk, and vulnerability of winter wheat waterlogging in spring over the middle and lower reaches of Yangtze River, and proposed an integrated waterlogging risk assessment model. The spatial distribution of waterlogging risk was derived by using multivariate waterlogging indices, and the study area was classified into high, relatively high, medium and low risk levels. The secondary-risk to high-risk areas of waterlogging mainly distributed in the plain regions of Hubei Province, in addition the plain and polder areas along Yangtze River across Anhui and Jiangsu Provinces.

Due to the complexity of the formation, development, and consequences of waterlogging, there still exists varying degree of uncertainty in waterlogging risk assessment caused by the relative subjective selection of environmental factors. To alleviate the uncertainty caused by a single environmental factor in waterlogging risk assessment, the waterlogging risk from topography, soil, and meteorology, including the risk and vulnerability of hazard-affected body, i.e., winter wheat were synthetically assessed. However, it's noted that crops generally have different risk resistance capacities in each phenology stage. So, it's still a challenge to combine the waterlogging risk resistance capacities of winter wheat in different growth stages to dynamically provide waterlogging risk assessment at regional scale.

\section{Acknowledgments}

This work is supported by the special fund for industrial scientific research in the public interest (Meteorology) (Grant No. GYHY201406028) and National Natural Foundation of China (Grant No. 41371412-D010702). The authors appreciate the valuable comments by the anonymous reviewers.

\section{[References]}

[1] Drew M C. Oxygen deficiency and root metabolism: injury and acclimation under hypoxia and anoxia. Annual Review of Plant Biology, 1997; 48(4): 223-250.

[2] Bailey-Serres J, Voesenek L A C J. Flooding stress: acclimations and genetic diversity. Plant Biology, 2008; 59(59): 313-339.

[3] Voesenek L A C J, Sasidharan R. Ethylene - and oxygen signalling drive plant survival during flooding. Plant Biology, 2013; 15(3): 426-435.

[4] Barrett-Lennard E G. The interaction between waterlogging and salinity in higher plants: causes, consequences and implications. Plant \& Soil, 2003; 253(1): 35-54.

[5] Pociecha E, Kościelniak J, Filek W. Effects of root flooding and stage of development on the growth and photosynthesis of field bean (Vicia faba L. minor). Acta Physiologiae Plantarum, 2008; 30(4): 529-535.

[6] Shaw R E, Meyer W S, Mcneill A, Tyerman S D. Waterlogging in Australian agricultural landscapes: a review of plant responses and crop models. Crop \& Pasture Science, 2013; 64(6): 549-562.
[7] Colmer T D, Voesenek L A C J. Flooding tolerance: suites of plant traits in variable environments. Functional Plant Biology, 2009; 36(8): 665-681.

[8] Cannell R Q, Belford R K, Gales K, Dennis C W, Prew R D. Effects of waterlogging at different stages of development on the growth and yield of winter wheat. Journal of the Science of Food \& Agriculture, 1980; 31(2): $117-132$.

[9] Hossain M A, Araki H, Takahashi T. Poor grain filling induced by waterlogging is similar to that in abnormal early ripening in wheat in Western Japan. Field Crops Research, 2011; 123(2): 100-108.

[10] Evans R O, Fausey N R, Skaggs R W, Schilfgaarde J V. Effects of inadequate drainage on crop growth and yield. Agricultural Drainage, 1999.

[11] Setter T L, Waters I. Review of prospects for germplasm improvement for waterlogging tolerance in wheat, barley and oats. Plant \& Soil, 2003; 253(1): 1-34.

[12] Boru G, Ginkel M V, Kronstad W E, Boersma L. Expression and inheritance of waterlogging tolerance stress in wheat. Euphytica, 2000; 117(2): 91-98.

[13] Ghorai A K, Bhattacharjee A K, Saha S, Rao P V. Effect of waterlogging and drainage on yield and quality of jute (Corchorus olitorius and Corchorus capsularis). Journal of Water Management, 2003; 11(2): 68-73.

[14] Jayan P R, Sathyanathan N. Overview of farming practices in the water-logged areas of Kerala, India. Int J Agric \& Biol Eng, 2010: 3(4): 28-43.

[15] Macewan R J, Crawford D M, Newton P J, Clune T S. High clay contents, dense soils, and spatial variability are the principal subsoil constraints to cropping the higher rainfall land in south-eastern Australia. Australian Journal of Soil Research, 2010; 48(2): 150-166.

[16] Liu M, Yang H Q, Xiang Y C. Risk assessment and regionalization of waterlogging disasters in Hubei Province. Resources \& Enuironment in the Yangtza Basin, 2002; 11(5): 476-481.

[17] Gao C, Zhang Z, Zhai J, Liu Q, Yao M. Research on meteorological thresholds of drought and flood disaster: a case study in the Huai River Basin, China. Stochastic Environmental Research \& Risk Assessment, 2015; 29(1): 157-167.

[18] Sheng S X, Shi L, Zhang Y L. Study on waterlogging disaster index and risk assessment model of winter wheat in Jianghuai region. Chinese Agricultural Science Bulletin, 2009; 25(19): 263-268. (in Chinese)

[19] Mebarki A, Valencia N, Salagnac J L, Barroca B. Flood hazards and masonry constructions: a probabilistic framework for damage, risk and resilience at urban scale. Nat Hazards Earth Syst Sci, 2012; 12(5): 1799-1809.

[20] Neal J, Keef C, Bates P, Beven K, Leedal D. Probabilistic flood risk mapping including spatial dependence. Hydrological Processes, 2013; 27(9): 1349-1363.

[21] Paulo A A, Pereira L S. Prediction of SPI drought class transitions using Markov chains. Water Resources Management, 2007; 21(10): 1813-1827.

[22] Souther S, Mcgraw J B. Vulnerability of wild American ginseng to an extreme early spring temperature fluctuation. Population Ecology, 2011; 53(1): 119-129.

[23] Tingsanchali T, Karim M F. Flood hazard and risk analysis in the southwest region of Bangladesh. Hydrological Processes, 2005; 19(10): 2055-2065.

[24] Wang Z, Jiang J, Ma Q. The drought risk of maize in the farming-pastoral ecotone in Northern China based on physical vulnerability assessment. Nat Hazards Earth Syst Sci, 2016; 16(12): 2697-2711.

[25] Sobowale A, Oyedepo J A. Status of flood vulnerability area in an ungauged basin, southwest Nigeria. Int J Agric \& Biol Eng, 2013; 6(2): 28-36.

[26] She B, Huang J F, Zhang D Y, Huang L S. Assessing and characterizing oilseed rape freezing injury based on MODIS and MERIS data. Int $\mathrm{J}$ Agric \& Biol Eng, 2017; 10(3): 143-157.

[27] Mpelasoka F, Hennessy K, Jones R, Bates B. Comparison of suitable drought indices for climate change impacts assessment over Australia towards resource management. International Journal of Climatology, 2008; 28(10): 1283-1292.

[28] Santander A, Vargas X, Demuth S, Gustard A, Planos E, Seatena F, et al. Indices and grades of regional flood risk in a flood alert system: use of fuzzy logic. Climate Variability \& Change: Hydrological Impacts. Wallingford: IAHS Press; 2006; p.207-213. 
[29] Xing Z, Yang Z, Fu Q, Li H, Gong X, Wu J. Characteristics and risk assessment of agricultural meteorological disasters based on 30 years' disaster data from Heilongiiang Province of China. Int J Agric \& Biol Eng, 2017; 10(6): 144-154.

[30] Cox J W, Mcfarlane D J, Skaggs R W. Field-evaluation of DRAINMOD for predicting waterlogging intensity and drain performance in South-Western Australia. Soil Research, 1994; 32(4): 653-671.

[31] Wang X, Mosley C T, Frankenberger J R, Kladivko E J. Subsurface drain flow and crop yield predictions for different drain spacings using DRAINMOD. Agricultural Water Management, 2006; 79(2): 113-136.

[32] Wang X, Deng Z, Zhang W, Meng Z, Chang X, Lv M. Effect of waterlogging duration at different growth stages on the growth, yield and quality of cotton. Plos One, 2017; 12(1): e0169029.

[33] Shao G C, Lan J J, Yu S E, Liu N, Guo R Q, She D L. Photosynthesis and growth of winter wheat in response to waterlogging at different growth stages. Photosynthetica, 2013; 51(3): 429-437.

[34] Malik A I, Colmer T D, Lambers H, Setter T L, Schortemeyer M. Short-term waterlogging has long-term effects on the growth and physiology of wheat. New Phytologist, 2002; 153(2): 225-236.

[35] Hossain M A, Uddin S N. Mechanisms of waterlogging tolerance in wheat: Morphological and metabolic adaptations under hypoxia or anoxia. Australian Journal of Crop Science, 2011; 5(9): 1094-1101.

[36] Wu H Y, Gao P, Xu W G, Bao Y X. Risk division on winter wheat suffering from spring wet damages in Jiangsu Province. Acta Ecologica Sinica, 2012; 32(6): 1871-1879.

[37] Huang D P, Liu C, Fang H, Peng S F. Assessment of waterlogging risk in Lixiahe region of Jiangsu Province based on AVHRR and MODIS image. Chinese Geographical Science: English Edition, 2008; 18(2): 178-183.
[38] Singh K V, Setia R, Sahoo S. Evaluation of NDWI and MNDWI for assessment of waterlogging by integrating digital elevation model and ground water level. Geocarto International, 2014; 30(6): 650-661.

[39] Shi P J. Theory and practice on disaster system research in a fourth time. Journal of Natural Disasters, 2005; 14(6): 1-7.

[40] Mahdi I M, Alreshaid K. Decision support system for selecting the proper project delivery method using analytical hierarchy process (AHP). International Journal of Project Management, 2005; 23(7): 564-572.

[41] Rowell D L. Soil science: methods and applications. Geoderma, 1995; 66(6): 160-161.

[42] Ingleby N B, Lorenc A C. Bayesian quality control using multivariate normal distributions. Quarterly Journal of the Royal Meteorological Society, 1993; 119(513): 1195-1225.

[43] Box G E P, Cox D R. An analysis of transformations. Journal of the Royal Statistical Society Series B (Methodological), 1964; 26(2): 211-252.

[44] Adger W N. Vulnerability. Global Environmental Change, 2006; 16(3): 268-281.

[45] Fuchs S, Birkmann J, Glade T. Vulnerability assessment in natural hazard and risk analysis: current approaches and future challenges. Natural Hazards, 2012; 64(3): 1969-1975.

[46] Ge Q S, Zhou M, Zheng J Y. Preliminary study of comprehensive risk evaluation of Chinese natural disaster. Beijing, China: Science Press, 2008.

[47] Shahid S, Behrawan H. Drought risk assessment in the western part of Bangladesh. Natural Hazards, 2008; 46(3): 391-413.

[48] Sheng S X, Huo Z G, Shi L. Risk assessment and regionalization of waterlogging disaster for wheat in Jianghuai Region. Chinese Journal of Ecology, 2010; 29(5): 985-990. 